\title{
Environmental impact on physical activity and health in transgender youth
}

\begin{abstract}
Background: Physical Activity Guidelines for Americans suggest that youth should participate in at least one hour of age appropriate PA per day. Yet, fewer than 30\% of high school students participate in at least 60 minutes of PA every day; ethnic minority youth report even less. Within the transgender community, students were less likely to be physically active, due to safety concerns which is mostly related to a sedentary adult. Purpose: To investigate the barriers and facilitators transgender adults faced when they were adolescents and experiencing PA environments (e.g. physical education, sport teams). Methods: Quantitative study using a questionnaire with 27 closed-ended questions. A sample of convenience was used to recruit participants. Data was coded, cleaned, and analyzed using Microsoft Excel 2018 and SPSS Statistics 24. Results: Quantitative results indicate that there is transphobic behavior present in a physical activity environment, furthermore, facilities prevented participants from participating in physical activity. Implications: The results of this study may possibly be used to inform programming in educational institutions, coaches, and support policy makers in developing what interventions are needed to increase safety for transgender youth.
\end{abstract}

KEYwords: Physical Activity; Youth; Transgender.

\section{Purpose}

Transgender people have faced layers of discrimination in physical activity (PA) settings; sport, recreation, and physical education (PE). Physical and mental health are shown to be positively associated with social support, social network size, and the non-use of drugs ${ }^{1}$. Transgender adults were surveyed to understand health risk behaviors, finding major differences between transgender adults and cisgender adults in relation to substance use, exercise, and diet. Transgender adults practice self-harm, smoke daily, and were considered binge drinkers compared to their cisgender peers ${ }^{2}$.

Being physically active reduces risk for some cancers, diabetes, and cardiovascular disease while simultaneously improving mood, and physical and mental health. Regularly participating in PA reduces the risk of becoming clinically depressed, which is one of many mental health concerns ${ }^{3}$. Adults that identify as being lesbian, gay, or bisexual (LGB) have less participation in PA compared to those that identify as heterosexual ${ }^{4}$. Yet, recent studies indicate an overall lower level of participation in PA by transgender adults compared to their cisgender peers due to body satisfaction, selfesteem, and depression ${ }^{5}$.

One step to improve overall fitness at any age is to become physically active. PA guidelines for Americans suggest that youth should participate in at least one hour of age appropriate PA per day ${ }^{6}$; yet fewer than $30 \%$ of high school students participate in at least 60 minutes of PA every day and larger disparities in minority groups ${ }^{7}$. Transgender college students are less likely to be physically active, more likely to be obese or underweight, and have increased time spent on screen devices compared to their cisgender peers ${ }^{8}$. Within the transgender 
community, transwomen are reported to have lower rates of participation in PA, but the reasons for this are unclear ${ }^{2,9}$.

Transphobia is highest in the school setting, where youth spend most of their day. Students experience victimization from their peers, harassment by their teachers, and tend to frequently transfer schools ${ }^{10}$. Interventions within the transgender community should provide a safe and inclusive space specifically for those that identify as transgender ${ }^{8}$. Despite efforts to provide a safe space, those involved must also consider the unique situations that individuals face when transitioning. For example, at the start of a class, educators can ask students to introduce themselves and include their preferred pronouns, so the individual's identity is not assumed.

Hostile climates for LGBTQ youth and exclusion of LGBTQ students often occur in PA settings ${ }^{11}$. One PA setting youth engage in weekly are PE classes. California requires elementary school students participate in a total of 200 minutes every 10 school days whereas middle and high school

\section{Methods}

\section{Participants}

Participants for this study were recruited by the principal investigator using a sample of convenience. Friends and colleagues who identify as transgender were asked to participate in the study and share the study others that identify as transgender. Participants were asked to examine transphobic and heterosexist behavior within school PE classes, outside of school PA environments, and sport. This allowed the researcher to assess the ways that transgender people experience PA participation, environmental climate, and safety. This study was approved by the San Francisco State University Intuitional Review Board.

\section{Instruments}

Data was collected through a self-administered online questionnaire that participants filled out in their own time using Google form. Questions were drawn from current studies and existing questionnaires that examine healthy behavior, youth, and PA environments ${ }^{14,15}$. students participate in 400 minutes per 10 school days ${ }^{12}$. Therefore, LGBTQ youth rely on educators to provide a safe space.

PA settings are considered to be one of the more hostile environments for LGBTQ youth ${ }^{11}$. However, participation in PA may be dependent on what phase (pre-transition, currently transitioning, or post transition) participants are facing. Pre- and posttransition participants report being extremely active or never active, whereas those in their transition phase have shown a drop in their PA levels ${ }^{13}$. Future studies need to directly investigate behaviors, the climate, and perceptions in a PA setting, including settings such as gyms, fields, and other PA environments outside of schools. By obtaining information from transgender youth, intervention and policies at the city, state, or national level can be implemented in school and other outdoor recreation areas holding a potential impact on physical and mental health ${ }^{11}$. Therefore, this study aims to investigate the barriers and facilitators transgender adults faced when they were adolescents and experiencing PA environments.

How often have you personally experienced transphobic behavior from your classmates in your physical education classes (1 never, scaling to 5 always)?

How often have you personally experienced transphobic behavior from your coach? (1 never, scaling to 5 always)?

The researcher chose to administer an online questionnaire over a paper-based test to ensure participants chose an environment they considered safe; therefore, it was assumed that all questions were answered without the fear of judgment which may occur in a public setting. This approach also allowed participants to freely complete the survey in their own time.

\section{Data Analysis}

Survey data were transferred from Google surveys to Excel. The survey data were coded, cleaned, and analyzed using Microsoft Excel 2018 and SPSS Statistic 24. The researcher ran 1 statistical analysis: Pearson correlation coefficient.

Pearson correlation coefficient was used to determine the relationship among the ordinal, 
Likert scale, and nominal variables with interval variables. The researcher then ran Spearman's correlation, which allows data analysis between nominal variables to be observed. Tests were set at a significance of 0.05 ; a p-value greater than 0.05 indicates failed rejection of the null hypothesis.

\section{Results}

\section{Demographics}

A total of 50 adults participated in this study (Figure 1 by percentages). Primarily consisting of transgender females $(\mathrm{N}=36)$, followed by transgender men $(\mathrm{N}=10)$, and those that identified as gender fluid, bigender, or some variation that was not cisgender $(\mathrm{N}=4)$. Half of the participants $(\mathrm{N}=25)$ identified as bisexual; while the remainder identified as lesbian $(\mathrm{N}=9)$, gay $(\mathrm{N}=4)$, heterosexual $(\mathrm{N}=4)$, and other $(\mathrm{N}=8)$. A majority of participants identified as white $(\mathrm{N}=$ 35); other racial identities were black or African American $(\mathrm{N}=3)$, Latin, Asian $(\mathrm{N}=6)$, and other $(\mathrm{N}=4)$. Participants ranged in age from 18 to $74(\mathrm{M}=42.34, \mathrm{SD}=18.03)$.

FIGURE 1 - Demographics by percent.

\section{Demographics}

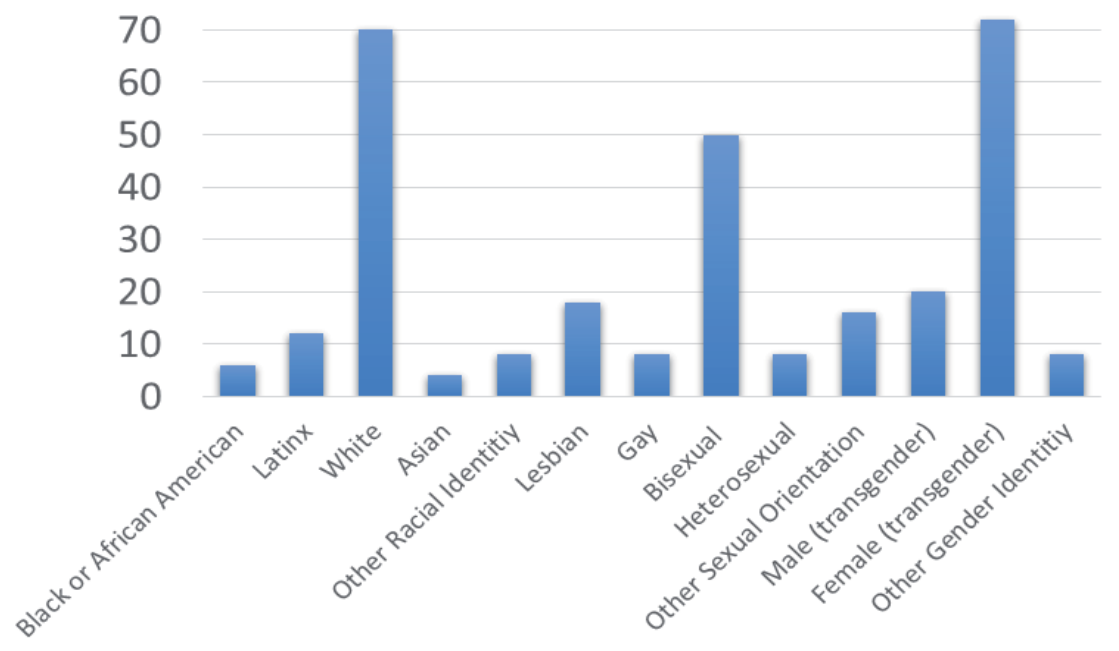

\section{Physical education}

All participants $(\mathrm{N}=50)$ assessed PE classes, potential transphobic behaviors (TBPE 1,2,3), use of role models (PETRM), safety (PESP), and PE teachers confronting transphobic behavior (PECTB). A Pearson's $\mathrm{r}$ data analysis revealed a high positive correlation $(\mathrm{r}=0.73)$ between students who witnessed transphobic behavior by students towards students (TBPE1) and experienced transphobic behavior by their classmates towards them (TBPE2). Students who saw more transphobic behavior in their PE classes reported experiencing higher levels of transphobic behavior towards themselves. A Pearson's $r$ data analysis revealed a moderate positive correlation $(r=0.69)$ between students who witnessed transphobic behavior by students towards students (TBPE1) and experienced transphobic behavior by their PE teacher towards them (TBPE3), indicating that those who witnessed transphobic behavior in their PE class also experienced higher levels of transphobic behavior 
${ }^{* *}$ Correlation is significant at the 0.01 level (2-tailed). by their PE teacher. A Pearson's $r$ data analysis also revealed a high positive correlation $(r=0.8)$ within students who experienced transphobic behavior by their classmates towards them (TBPE2) and experienced transphobic behavior by their PE teacher towards them (TBPE3), revealing that those who experienced transphobic behavior by their classmates faced higher levels of transphobic behavior by their PE teacher. Finally, a Pearson's $\mathrm{r}$ data analysis revealed a moderate positive correlation $(r=0.43)$ with PE teachers who used transgender role models (PETRM) and PE teachers who confronted transphobic behavior (PECTB). So, teachers who used transgender role models were also likely to confront transphobic behavior in their classrooms.

TABLE 1 - Physical education correlations.

\begin{tabular}{|c|c|c|c|c|c|c|c|}
\hline & & TBPE1 & TBPE2 & TBPE3 & PETRM & PESP & PECTB \\
\hline \multirow[t]{3}{*}{ TBPE1 } & $\begin{array}{l}\text { Pearson } \\
\text { Correlation }\end{array}$ & 1 & & & & & \\
\hline & Sig. (2-tailed) & & & & & & \\
\hline & $\mathrm{N}$ & 50 & & & & & \\
\hline \multirow[t]{3}{*}{ TBPE2 } & $\begin{array}{l}\text { Pearson } \\
\text { Correlation }\end{array}$ & $.728^{* *}$ & 1 & & & & \\
\hline & Sig. (2-tailed) & 0 & & & & & \\
\hline & $\mathrm{N}$ & 50 & 50 & 50 & & & \\
\hline \multirow[t]{3}{*}{ TBPE3 } & $\begin{array}{l}\text { Pearson } \\
\text { Correlation }\end{array}$ & $.685^{* *}$ & $.797^{* *}$ & 1 & & & \\
\hline & Sig. (2-tailed) & 0 & 0 & & & & \\
\hline & $\mathrm{N}$ & 50 & 50 & 50 & & & \\
\hline \multirow[t]{3}{*}{ PETRM } & $\begin{array}{l}\text { Pearson } \\
\text { Correlation }\end{array}$ & -0.052 & 0.04 & 0.048 & 1 & & \\
\hline & Sig. (2-tailed) & 0.722 & 0.784 & 0.743 & & & \\
\hline & $\mathrm{N}$ & 50 & 50 & 50 & 50 & & \\
\hline \multirow[t]{3}{*}{ PESP } & $\begin{array}{l}\text { Pearson } \\
\text { Correlation }\end{array}$ & -0.065 & -0.082 & -0.216 & 0.065 & 1 & \\
\hline & Sig. (2-tailed) & 0.656 & 0.57 & 0.132 & 0.654 & & \\
\hline & $\mathrm{N}$ & 50 & 50 & 50 & 50 & 50 & \\
\hline \multirow[t]{3}{*}{ РECTB } & $\begin{array}{l}\text { Pearson } \\
\text { Correlation }\end{array}$ & 0.18 & 0.188 & 0.173 & $.429^{* *}$ & 0.191 & 1 \\
\hline & Sig. (2-tailed) & 0.211 & 0.191 & 0.23 & 0.002 & 0.185 & \\
\hline & $\mathrm{N}$ & 50 & 50 & 50 & 50 & 50 & 50 \\
\hline
\end{tabular}

Sport - Some $(32 \%, N=16)$ of those surveyed did not participate in sport at all; while a majority $(68 \%$, $\mathrm{N}=34$ ) participated in a sport either associated with their school $(\mathrm{N}=29,85.3 \%)$, or with a sport team not through their school $(\mathrm{N}=5,14.7 \%)$.
Correlations - A Pearson's $r$ data analysis revealed a high positive correlation $(r=0.76)$ between youth who witnessed transphobic behavior by teammates towards other teammates (TBS1) and experienced transphobic behavior by their 
teammates towards themselves (TBS2). Youth who saw more transphobic behavior by their teammates towards other teammates reported experiencing higher levels of transphobic behavior towards themselves. A Pearson's $\mathrm{r}$ data analysis revealed a moderate positive correlation ( $\mathrm{r}=$ 0.65 ) between youth who witnessed transphobic behavior by teammates towards other teammates (TBS1) and experienced transphobic behavior by their coach towards themselves (TBS3), indicating that those who witnessed transphobic behavior by their teammates towards other teammates also experienced higher levels of transphobic behavior by their coaches. A Pearson's $r$ data analysis revealed a high positive correlation $(\mathrm{r}=0.78)$ within youth who experienced transphobic behavior by their teammates towards themselves (TBS2) and experienced transphobic behavior by their coach towards themselves(TBS3), indicating that those who experienced transphobic behavior by their teammates also faced higher levels of transphobic behavior by their coaches. A Pearson's $r$ data analysis also revealed a high positive correlation $(r=0.84)$ with coaches that confront transphobic behavior (CCTB) and coaches that use transgender role models (CTRM). So, coaches that confronted transphobic behavior also used transgender role models as examples.

TABLE 2 - Sport Correlations.

\begin{tabular}{|c|c|c|c|c|c|c|c|}
\hline & & TBS1 & TBS2 & TBS3 & CTRM & CSP & ССТВ \\
\hline \multirow[t]{3}{*}{ TBS1 } & $\begin{array}{l}\text { Pearson } \\
\text { Correlation }\end{array}$ & 1 & & & & & \\
\hline & Sig. (2-tailed) & & & & & & \\
\hline & $\mathrm{N}$ & 36 & & & & & \\
\hline \multirow[t]{3}{*}{ TBS2 } & $\begin{array}{l}\text { Pearson } \\
\text { Correlation }\end{array}$ & $.763^{* *}$ & 1 & & & & \\
\hline & Sig. (2-tailed) & 0 & & & & & \\
\hline & $\mathrm{N}$ & 35 & 35 & & & & \\
\hline \multirow[t]{3}{*}{ TBS3 } & $\begin{array}{l}\text { Pearson } \\
\text { Correlation }\end{array}$ & $.647^{* *}$ & $.784^{* *}$ & 1 & & & \\
\hline & Sig. (2-tailed) & 0 & 0 & & & & \\
\hline & $\mathrm{N}$ & 35 & 35 & 35 & & & \\
\hline \multirow[t]{3}{*}{ CTRM } & $\begin{array}{l}\text { Pearson } \\
\text { Correlation }\end{array}$ & 0.022 & 0.152 & 0.33 & 1 & & \\
\hline & Sig. (2-tailed) & 0.9 & 0.384 & 0.053 & & & \\
\hline & $\mathrm{N}$ & 35 & 35 & 35 & 35 & & \\
\hline \multirow[t]{3}{*}{ CSP } & $\begin{array}{l}\text { Pearson } \\
\text { Correlation }\end{array}$ & -0.081 & -0.254 & -0.11 & 0.251 & 1 & \\
\hline & Sig. (2-tailed) & 0.644 & 0.141 & 0.527 & 0.146 & & \\
\hline & $\mathrm{N}$ & 35 & 35 & 35 & 35 & 35 & \\
\hline \multirow[t]{3}{*}{ ССТВ } & $\begin{array}{l}\text { Pearson } \\
\text { Correlation }\end{array}$ & -0.059 & 0.059 & 0.226 & $.837^{* *}$ & 0.287 & 1 \\
\hline & Sig. (2-tailed) & 0.738 & 0.736 & 0.191 & 0 & 0.095 & \\
\hline & $\mathrm{N}$ & 35 & 35 & 35 & 35 & 35 & 35 \\
\hline
\end{tabular}

** Correlation is significant at the 0.01 level (2-tailed). 
Physical activity - Based on participants who responded, "I only did PE.," the researcher infers that the amount of missing data $(n=5)$ in this section is due to participants only taking part in $\mathrm{PE}$ classes or sport teams, and not working out in other PA settings.

Correlations - A Pearson's $r$ data analysis revealed a high positive correlation $(\mathrm{r}=0.8)$ between youth who witnessed transphobic behavior by youth towards other youth (TBPA1) and reported transphobic behavior by youth towards adults (TBPA2), indicating that youth who witnessed transphobic behavior by youth towards other youth had a higher report of witnessing transphobic behavior by youth towards adults. A Pearson's $r$ data analysis revealed a high positive correlation $(\mathrm{r}$ $=0.72$ ) between youth who witnessed transphobic behavior by youth towards other youth (TBPA1) and youth who witnessed transphobic behavior by adults towards other youth (TBPA3), identifying that youth who observed transphobic behavior by youth towards other youth had a high response in seeing transphobic behavior by adults towards youth. A Pearson's $r$ data analysis revealed a moderate positive correlation $(r=0.68)$ between transphobic behavior by youth towards adults (TBPA2) and youth who witnessed transphobic behavior by adults towards other youth (TBPA3). Youth who saw transphobic behavior by youth towards adults also reported seeing adults discriminate against youth. A Pearson's $r$ data analysis revealed a high positive correlation $(\mathrm{r}=$ 0.74 ) between youth who witnessed transphobic behavior by youth towards other youth (TBPA1) and transphobic behavior towards themselves by adults (TBPA4). Youth who witnessed transphobic behavior by youth towards youth were also likely to experience transphobic behavior by adults. A Pearson's $r$ data analysis revealed a high positive correlation $(r=0.83)$ between transphobic behavior by youth towards adults (TBPA2) and transphobic behavior towards themselves by adults (TBPA4). Youth who observed transphobic behavior by youth towards adults also faced discrimination by adults. A Pearson's $r$ data analysis revealed a high positive correlation $(r=0.76)$ for youth who witnessed transphobic behavior by adults towards other youth (TBPA3) and transphobic behavior towards themselves by adults (TBPA4). Therefore, those that observed transphobic behavior by adults towards youth also experienced transphobic behavior by adults. A Pearson's $r$ data analysis revealed a high positive correlation $(r=0.8)$ between youth who witnessed transphobic behavior by youth towards other youth (TBPA1) and transphobic behavior towards themselves by youth (TBPA5). Youth who saw more transphobic behavior by youth towards youth reported experiencing higher levels of transphobic behavior towards them. A Pearson's $r$ data analysis revealed a moderate high correlation $(\mathrm{r}=0.7)$ between transphobic behavior by youth towards adults (TBPA2) and transphobic behavior towards themselves by youth (TBPA5). Youth who saw transphobic behavior by youth towards adults had higher reports of youth discriminating against them. A Pearson's $r$ data analysis revealed a moderate positive correlation $(r=0.63)$ for youth who witnessed transphobic behavior by adults towards other youth (TBPA3) and transphobic behavior towards themselves by youth (TBPA5). Youth who observed transphobic behavior by adults towards youth also faced transphobic behavior by youth. A Pearson's $r$ data analysis revealed a strong positive correlation $(\mathrm{r}=0.7)$ that those who faced transphobic behavior towards themselves by adults (TBPA4) also experienced transphobic behavior towards themselves by youth (TBPA5), finally concluding that youth who were discriminated by adults were also discriminated against their peers. 
TABLE 3 - Physical activity correlations.

\begin{tabular}{|c|c|c|c|c|c|c|}
\hline & & TBPA1 & TBPA2 & TBPA3 & TBPA4 & TBPA5 \\
\hline \multirow[t]{3}{*}{ TBPA1 } & $\begin{array}{l}\text { Pearson } \\
\text { Correlation }\end{array}$ & 1 & & & & \\
\hline & Sig. (2-tailed) & & & & & \\
\hline & $\mathrm{N}$ & 45 & & & & \\
\hline \multirow[t]{3}{*}{ ТВРА2 } & $\begin{array}{l}\text { Pearson } \\
\text { Correlation }\end{array}$ & $.801^{* *}$ & 1 & & & \\
\hline & Sig. (2-tailed) & 0 & & & & \\
\hline & $\mathrm{N}$ & 45 & 45 & & & \\
\hline \multirow[t]{3}{*}{ ТВРА3 } & $\begin{array}{l}\text { Pearson } \\
\text { Correlation }\end{array}$ & $.721^{* *}$ & $.683^{* *}$ & 1 & & \\
\hline & Sig. (2-tailed) & 0 & 0 & & & \\
\hline & $\mathrm{N}$ & 44 & 44 & 44 & & \\
\hline \multirow[t]{3}{*}{ TBPA4 } & $\begin{array}{l}\text { Pearson } \\
\text { Correlation }\end{array}$ & $.735^{* *}$ & $.828^{* *}$ & $.755^{* *}$ & 1 & \\
\hline & Sig. (2-tailed) & 0 & 0 & 0 & & \\
\hline & $\mathrm{N}$ & 45 & 45 & 44 & 45 & \\
\hline \multirow[t]{3}{*}{ TBPA5 } & $\begin{array}{l}\text { Pearson } \\
\text { Correlation }\end{array}$ & $.802^{* *}$ & $.704^{* *}$ & $.633^{* *}$ & $.701^{* *}$ & 1 \\
\hline & Sig. (2-tailed) & 0 & 0 & 0 & 0 & \\
\hline & $\mathrm{N}$ & 45 & 45 & 44 & 45 & 45 \\
\hline
\end{tabular}

\section{Discussion}

The current study aimed to identify the barriers and facilitators transgender people have faced in three PA environments as youth; PE, sport, and recreation. The findings of this study contribute to the missing literature regarding the PA experiences of transgender people. Within this study there were an array of answers, which may be due to the age range of participants and will be discussed further in the limitation section. Correlations identified the multiple ways in which transphobic behavior is present in a PA environment, furthermore, when transgender role models are used, the adult (PE teacher or coach) will also confront transphobic behavior exhibited by youth. The participants did reflect on events that occurred years ago and results may be reported different in the current physical culture, indicating a need for further research.

\section{Physical education}

Correlations showed that if PE teachers failed to confront transphobic behavior, they simultaneously did not create a safe space for all youth. By educators not taking an active role, some students reported only participating in PA when forced ${ }^{8,14}$, 16. The barriers present in this environment forced participants to actively engage in gendered activities in order to blend in, however, participants suggested that all-gender activities would have motivated them in $\mathrm{PA}^{17}$.
** Correlation is significant at the 0.01 level (2-tailed). 
Correlations revealed a positive linear score, meaning those that faced adversity by their peers or PE teacher also witnessed transphobic behavior by students towards other students which is similar to reports in the literature with LGBT students addressing heterosexist and homophobic behavior in PE classes ${ }^{14}$. Descriptive statistics identified the variability in responses for each variable except for PE teachers never using transgender role models.

\section{Sport}

Similarly, the results in sport are parallel with $\mathrm{PE}$, correlations revealing the impact coaches have on their team and the team cohesion. This may be due to the participants being involved in sports that are associated with their school, therefore, participants will behave the same way as if they were in the classroom. However, there is variability in participants responses, which, as mentioned, can be due to the age range of the participants.

\section{Physical Activity}

Correlations indicated that all variables reported here served to create a hostile and unsafe environment for transgender participants, creating a domino effect of marginalization, as indicated in the literature 16. However participants were not blending in as their preferred gender, rather, they were presenting as their natal sex and may be due to the age group of the participants; the researcher has assumed that most of the participants were not expressing their gender at this time in their life.

These findings can be used by those in academia, sport, and recreation to provide a safer and more inclusive space for those that identify as transgender.

\section{Limitations}

Although this study provided foundational information to the current literature, participants' age range was a major limitation for many reasons. First, the term transgender itself was not widely known until recently, despite there being information about 'cross-dressers,' 'transsexuals,' and others not identifying as cisgender. Moreover, those that identify as transgender now, may not have presented their gender in school then, therefore, when reflecting back to their experiences, they may have been presenting as their natal sex, mitigating the behavior that could have occurred. Also, the term transphobia was not widely used because the term transgender was not present in society until the late 1900 's. Therefore, for those that were older, the questions could have been harder to answer, or were answered in that way because the lack of awareness of the transgender community and transphobia.

Furthermore, a self-reported survey on PA environments may be subject to recall bias and other sources of error, such as recall. Because we asked participants to reflect back to an experience, their answers may have been skewed one way or another. Because the surveys were distributed using a sample of convenience method, participants can potentially have shared characteristics among themselves, as shown in the demographics, and could account for the correlation findings.

Finally, the reports in sport environment were similar, this could be due to the PE teacher also being the coach, the students in their PE class also being on their sport team, or because of the school environment having a wider impact on both PA environments.

\section{Suggestions for future research}

The following suggestions are based on the findings of the current study, the study limitations, and the current literature, reviewed above. Based on the limitations of the study, future researchers should repeat the study with the following adjustments;

- Observe a younger demographic (those currently in school).

- Equally dividing those associated with school sport and sports not associated with the school to participate in the study, researchers can then run and ANOVA to test the differences in these sporting environments.

- Examine a singular PA environment (e.g. sport, $\mathrm{PE}$, or recreational PA)

- Test the PE environment through PE teachers' responses and students' responses

- Test the relationship between PE classes transphobic behavior and the entire schools' environment.

- Finally, researchers can examine each environment individually.

However, based on the literature, researchers can also test the following;

- Participation in PA in cisgender youth and transgender youth.

- Participation in PA in transgender boys and transgender girls. 


\section{References}

1. Fredriksen-Goldsen KI, Kim H, Shiu C, Goldsen J, Emlet CA. Successful aging among LGBT older adults: physical and mental health-related quality of life by age group. The Gerontologist. 2014;55(1):154-168.

2. Smalley KB, Warren JC, Barefoot KN. Differences in health risk behaviors across understudied LGBT subgroups. Health Psychol. 2016;35(2):103-114.

3. Centers for Disease Control. Prevention Physical Activity. 2018 [Internet]. Available from https://www.cdc.gov/physicalactivity/basics/pa-health/index.htm

4. Mereish EH, Poteat VP. Let's get physical: sexual orientation disparities in physical activity, sports involvement, and obesity among a population-based sample of adolescents. Am J Public Health. 2015;105(9):1842-1848.

5. Jones BA, Haycraft E, Bouman WP, Arcelus J. The levels and predictors of physical activity engagement within the treatment-seeking transgender population: a matched control study. J Phys Activity Health. 2018;15(2):99-107.

6. Office of Disease Prevention and Health Promotion. Physical Activity Guidelines for Americans Summary. 2008. Available from https://health.gov/paguidelines/guidelines/summary.aspx

7. Centers for Disease Control Facts about Physical Activity. 2014. Available from https://www.cdc.gov/physicalactivity/ data/facts.htm

8. VanKim NA, Erickson DJ, Eisenberg ME, Lust K, Rosser BR, Laska MN. Weight-related disparities for transgender college students. Health Behavior Policy Rev. 2014;1(2):161-171.

9. Olsen EM, Kann L, Vivolo-Kantor A, Kinchen S, McManus T. School violence and bullying among sexual minority high school students. 2009-2011. J Adolescent Health. 2014;55(3):432-438.

10. McGuire JK, Anderson CR, Toomey RB, Russell ST. School climate for transgender youth: a mixed method investigation of student experiences and school responses. J Youth Adolescence. 2010;39(10):1175-1188. d

11. Gill DL, Morrow RG, Collins KE. Lucey AB, Schultz AM. Perceived climate in physical activity settings. J Homosexuality. 2010;57(7):895-913.

12. SHAPE America. State Profiles. 2018 [Internet]. [cited May 4 2019]. Available from https://www.shapeamerica.org/ advocacy/son/2010/upload/California-profile.pdf

13. Elling-Machartzki A. Extraordinary body-self narratives: sport and physical activity in the lives of transgender people. Leisure Studies. 2015;36(2):256-268

14. Morrow RG, Gill DL. Perceptions of homophobia and heterosexism in physical education. Res Quarterly Exercise Sport. 2003;74(2): 205-14.

15. Caperchione CM, Chau S, Walker GJ, Mummery WK, Jennings C. Gender-associated perceptions of barriers and motivators to physical activity participation in south Asian Punjabis living in Western Canada. J Phys Activity Health. 2015;12(5):686-693.

16. Hargie OD, Mitchell DH, Somerville IJ. 'People have a knack of making you feel excluded if they catch on to your difference': transgender experiences of exclusion in sport. Intern Rev Sociol Sport. 2016;52(2):223-239.

17. Azzarito L, Katzew A. Performing identities in Physical Education: (en)gendering fluid selves. Res Quarterly Exercise Sport. 2010;81(1):25-37.

\begin{tabular}{r|r} 
ADDRESS & \\
Alexandria Ferrey & \\
Teachers College & Submitted: 04/29/2020 \\
Columbia University & Accept: 07/01/2020 \\
525 West 120th Street & \\
allieferrey@gmail.com &
\end{tabular}

